\title{
Energy Harvesting Techniques for Wireless Sensor Networks/Radio-Frequency Identification: A Review
}

\author{
Mohammed H. Alsharif ${ }^{1}\left(\mathbb{D}\right.$, Sunghwan Kim ${ }^{2, *} \mathbb{D}$ and Nuri Kuruoğlu ${ }^{3}$ \\ 1 Department of Electrical Engineering, College of Electronics and Information Engineering, Sejong University, \\ 209 Neungdong-ro, Gwangjin-gu, Seoul 05006, Korea \\ 2 School of Electrical Engineering, University of Ulsan, Ulsan 44610, Korea \\ 3 Faculty of Engineering and Architecture, Istanbul Gelisim University, Istanbul 34310, Turkey \\ * Correspondence: sungkim@ulsan.ac.kr; Tel.: +8-252-259-1401
}

Received: 4 June 2019; Accepted: 28 June 2019; Published: 3 July 2019

\begin{abstract}
In the near future, symmetry technologies for the Internet of Things (IoT), along with symmetry and asymmetry applications for IoT security and privacy, will re-design the socio-ecological human terrain morphology. The IoT ecosystem deploys diverse sensor platforms connecting billions of heterogeneous objects through the Internet. Most sensors are low-energy consuming devices which are designed to transmit sporadically or continuously. However, when we consider the billions/trillions of connected sensors powering various user applications, their energy efficiency (EE) becomes a critical issue. Therefore, the importance of EE in IoT technology cannot be overemphasised, specifically the development of EE solutions for sustainable IoT technology. Propelled by this need, EE proposals are expected to address IoT's EE issues. Consequently, many developments have been displayed, and highlighting them to provide clear insights into eco-sustainable and green IoT technologies is becoming a crucial task. To pursue a clear vision of green IoT, this article aims to describe the current state-of-the art insights into energy-saving practices and strategies on green IoT. The major contribution of this study is the review and discussion of the substantial issues enabling hardware green IoT to focus on green wireless sensor networks and green radio-frequency identification. This review paper will contribute significantly to the future implementation of green and eco-sustainable IoT.
\end{abstract}

Keywords: energy efficiency; eco-sustainability; RFID; WSNs; energy harvesting; green IoT

\section{Introduction}

The Internet of Things (IoT) is a paradigm which aims to advance telecommunications in all spheres of human life. In the near future, symmetry technologies for the Internet of Things (IoT), along with symmetry and asymmetry applications for IoT security and privacy, will re-design the socio-ecological human terrain morphology. This advancement leads to substantial improvement in quality of human life and the world's economic growth at large. IoT is considered the backbone of emerging applications (Figure 1) [1], as innovation plays a key role in the massive evolution of machine communications. Machine-to-machine (M2M) traffic is estimated to account for approximately $45 \%$ of the total Internet traffic by 2022 [2]. IoT creates a platform in which physical objects can mimic certain human sensory capabilities, such as perception, vision, hearing, smell and thinking. Buoyed by these human sensory capabilities and the emerging tactile Internet, machines can communicate with one another, share relevant information and make real-time decisions with less human input, especially now that we are migrating to the $5 \mathrm{G}$ era, in which the expected wireless network delay is $1 \mathrm{~ms}$. In this scenario, divergent sensors, such as radio-frequency identification (RFID) and sensing technology, can undertake the collaborative function of sensing, collecting and transmitting sensor information 
through the Internet [2]. Experts report that IoT holds incredible potential for smart homes, smart cities and healthcare applications [3]. Healthcare sectors can generate an annual revenue of \$1.1-2.5 trillion by 2025 [4]. Moreover, the worldwide economic effect of IoT is approximated at between $\$ 2.7$ and $\$ 6.2$ trillion by 2025 [2].

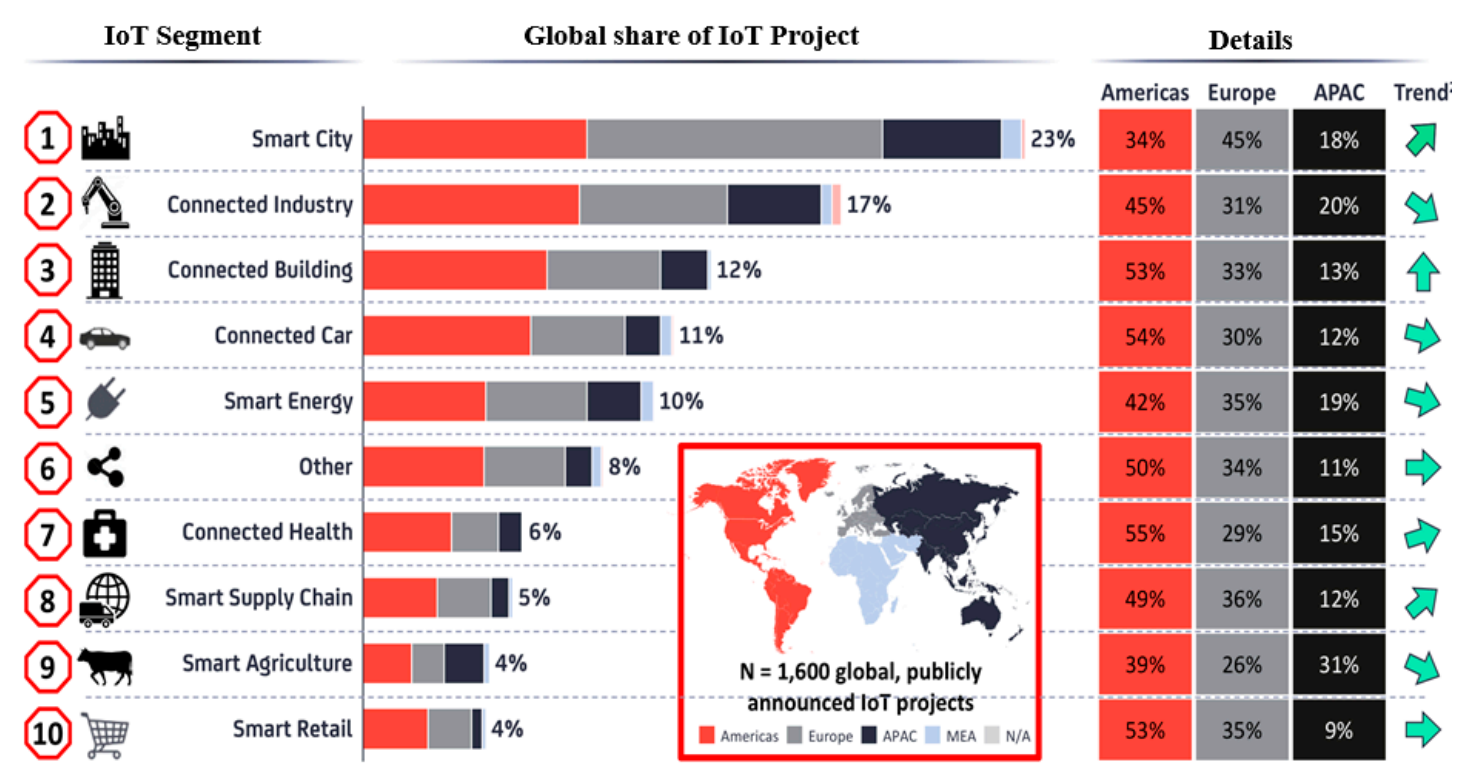

Figure 1. The most popular IoT applications (2018).

With the rise in ubiquitous IoT innovations, it has dawned on the telecom operators that innovative, and creative solutions are the essential tools needed to tackle the challenges and the potential of IoT. Today, the number of objects with Internet connectivity capability is greater than that of the Earth's population. As the capabilities of the IoT expand, it is expected that close to 50 billion devices will have Internet connectivity by 2020 [5]. Generally, the IoT will be capable of interconnecting billions/trillions of heterogeneous objects through the Internet by using different types of sensors like RFID and sensing technology. Both technologies will undertake collaborative functions of sensing, collecting and transmitting sensor information via the Internet.

Though active RFID tags are low energy consuming wireless devices [6], when these RFID tags are connected in an industrial scale involving billions of them, they generate millions of payload transmitted to the data centres for processing. To process these enormous sensor payload, huge processing and analytics capabilities are needed, which, in turn, consumes huge energy resources $[7,8]$. Herein, it is necessary to consider the issue of large-scale consumption of energy resources by IoTs. Motivated by this, a relatively novel research interest has evolved known as "green IoTs". This initiative not only tend to improve EE but also reduce the emission of $\mathrm{CO}_{2}$ from ICT products [9]. It is generally accepted that IoT will have great economic and ecological significance in years to come. Driven by these realities, it has become imperative to analyse the state-of-the art techniques and approaches capable of tackling the energy needs of these billions of energy hungry devices. Thus, the green IoT has become an important topic for researchers and vendors now more than ever as the conventional energy resources are dwindling and the energy consumption increasing exponentially.

Green IoT initiatives concentrate on the IoT EE. Thus, green IoT is defined as the process of achieving EE in IoT technology. This entails making every design process in IoT green until the implementation phase [10]. This has motivated researchers in both academia and industry to develop different techniques to improve IoT EE. Accordingly, research on the green IoTs encompasses wide spectrum of topics, research issues and challenges. Green IoT techniques can be classified into two main categories [11]: (i) Software, which focuses on energy wastage as a result of inefficient resource 
utilization, i.e., algorithms; and (ii) Hardware, which focuses on improving the EE in IoT components, and it is our target in this study.

In the recent times, green IoT survey papers have attracted wide attention [1,10,12-15]. The authors in [12] analysed various strategies for achieving green IoT; however, explicit green IoT models were never considered. Baliga et al. [13] discussed various cloud energy consumption scenarios. However, their models never discussed Quality of Service (QoS) metrics capable of increasing the energy consumption further in some scenarios. Reference [14] provided an in-depth discussions on energy harvesting in wireless sensor network (WSN) by exploiting various environmental resources. However, storing the harvested energy in a different medium other than the device will result in energy loss and hence, more work is needed in this regard. Reference [15] proposed that by implementing EE in heating, ventilating and air conditioning, could result in high energy saving design. Though extensive work has been done in the area of green IoT, energy conservation models are yet to be analysed. Reference [1] provided an extensive analysis of green IoT strategies, leading to the proposition of five green IoT principles. Moreover, the authors considered the case study approach to be a vital tool of IoT (in smart phones). However, the above studies lack depth in their explanation.

Since then, both sensor networking and RFID have been considered the two main pillars of IoT applications. In a hot research topic in ICT like green WSN and green RFID, there are many developments that quickly come into the spotlight and need to be highlighted in order to provide clear insights for researchers to choose the best solutions that provide green IoT and eco-sustainability. Thus, this review paper is different from the other review papers related to green IoT, in that this study gives full consideration to discussing green WSN and green RFID, which is considered one of the two main pillars of IoT applications, and this study aims to provide an overview of current state-of-the- art energy saving practices and strategies for green WSN and green RFID. To this end, this study tries to incorporate as many directions into this article as possible. Restricted by size constraints, the hot research topics have been investigated deeply based on their respective sub-domains to achieve a precise, concrete and concise conclusion at the end of this article. The key contributions of this study are summarized as follows:

- Presents an overview of popular research topics on green WSNs and RFID ecosystem, covering the recent industry development in the main areas of application, challenges and key players;

- Addresses several substantial design choices and features for WSNs and RFID, both of which are considered the top priorities of green IoT technologies. These features are deeply investigated on the basis of their respective sub-domains to achieve a precise, concrete and concise conclusion;

- Provides new references to other researchers who need insights into enabling hardware green IoT which provides eco-sustainability.

The organization of this article is as thus; Section 2 presents an overview of the green WSNs. Section 3 provides a detailed discussion of the RFID EE solutions. Finally, Section 4 concludes the work.

\section{Green Wireless Sensor Network}

Wireless sensors are an integral component of smart applications based on IoT technology. They are miniaturized, inexpensive devices equipped with the capability to detect parameter of interest and periodically transmit the results to the collection point. Mostly, they are powered by battery. A set of interconnected wireless sensors known as WSN is deployed. A WSN architecture comprises of wireless sensor nodes linked to a base station (BS) acting as the sink node. In formulating WSN standards, nodes source energy and computing resources are of great importance. Two topologies exist for WSN, which can either be infrastructure-based or infrastructure-less (ad-hoc)-based. In infrastructure topology, the BS performs the primary network core functions of; scheduling, resource allocation, interference management, routing and serving as the gateway to the local area network. Conversely, in infrastructure-less system architecture, there is no centralized BS, as each sensor can undertake the role of system coordination [16]. A description of low-power wireless sensor communication standards 
including: Long Range (LoRa), Bluetooth, LR-WPAN, Mobile communication, WiMAX, and WiFi is summarized in [17-19]. Table 1 provides a summarised comparison of wireless systems on the basis of notable attributes, such as standard, energy consumption, frequency band, data rate, transmission range and cost. Table 2 shows the suitability of these wireless technologies for IoT applications. Wireless sensors are designed to continuously and autonomously transmit data for a long period. WSNs that continuously send data are sensitive applications of weather forecast, traffic report, water quality, healthcare and embedded system. Wireless sensors are powered by batteries. However, the replacement or maintenance cost of exhausted batteries is prohibitive, and these batteries are difficult to replace, especially in remote locations due to geographical limitations (e.g., challenging terrain) [20]. Accordingly, developing energy-aware solutions to increase battery life and reduce replacement costs has become indispensable for WSN sustainability.

Table 1. Summary comparison of the using wireless technologies for IoT.

\begin{tabular}{|c|c|c|c|c|c|c|}
\hline Parameters & LoRa & Bluetooth & LR-WPAN & $\begin{array}{c}\text { Mobile } \\
\text { Communication }\end{array}$ & WiMAX & WiFi \\
\hline Standard & $\begin{array}{l}\text { LoRaWAN } \\
\quad \text { R1.0 }\end{array}$ & IEEE 802.15 .1 & $\begin{array}{c}\text { IEEE } \\
802.15 .4 \\
\text { (ZigBee) }\end{array}$ & $\begin{array}{c}\text { 2G-GSM, CDMA } \\
\text { 3G-UMTS, } \\
\text { CDMA2000 4G-LTE-A }\end{array}$ & IEEE 802.16 & $\begin{array}{l}\text { IEEE } 802.11 \\
\mathrm{a} / \mathrm{c} / \mathrm{b} / \mathrm{d} / \mathrm{g} / \mathrm{n}\end{array}$ \\
\hline $\begin{array}{c}\text { Energy } \\
\text { consumption }\end{array}$ & Very Low & $\begin{array}{l}\text { Bluetooth: } \\
\text { Medium; BLE: } \\
\text { Very Low }\end{array}$ & Low & Medium & Medium & High \\
\hline $\begin{array}{l}\text { Frequency } \\
\text { band }\end{array}$ & 868/900 MHz & $2.4 \mathrm{GHz}$ & $\begin{array}{c}868 / 915 \\
\mathrm{MHz}, 2.4 \\
\mathrm{GHz}\end{array}$ & $865 \mathrm{MHz}-2 . \mathrm{GHz}$ & $2-66 \mathrm{GHz}$ & $5-60 \mathrm{GHz}$ \\
\hline Data rate & $0.3-50 \mathrm{~Kb} / \mathrm{s}$ & $1-24 \mathrm{Mb} / \mathrm{s}$ & $40-250 \mathrm{~Kb} / \mathrm{s}$ & $200 \mathrm{~kb} / \mathrm{s}-1 \mathrm{~Gb} / \mathrm{s}$ & $\begin{array}{c}1 \mathrm{Mb} / \mathrm{s}-1 \mathrm{~Gb} / \mathrm{s} \\
\text { (Fixed) } 50-100 \mathrm{Mb} / \mathrm{s} \\
\text { (mobile) }\end{array}$ & $\begin{array}{c}1 \mathrm{Mb} / \mathrm{s}-6.75 \\
\mathrm{~Gb} / \mathrm{s}\end{array}$ \\
\hline $\begin{array}{l}\text { Transmission } \\
\text { range }\end{array}$ & $<30 \mathrm{Km}$ & $8-10 \mathrm{~m}$ & $10-20 \mathrm{~m}$ & Entire cellular area & $<50 \mathrm{Km}$ & 20-100 m \\
\hline Cost & High & Low & Low & Medium & High & High \\
\hline
\end{tabular}

Table 2. Suitability of wireless technologies for IoT applications.

\begin{tabular}{|c|c|c|c|c|c|c|}
\hline $\begin{array}{l}\text { Wireless } \\
\text { Technology }\end{array}$ & Healthcare & Smart Cities & $\begin{array}{c}\text { Smart } \\
\text { Building }\end{array}$ & Automotive & Industry & $\begin{array}{l}\text { Local Network } \\
\text { (M2M) }\end{array}$ \\
\hline Bluetooth (BLE) & very high & low & low & very low & very high & medium \\
\hline LR-WPAN & medium & high & low & very low & low & high \\
\hline LoRa & low & high & high & high & high & high \\
\hline WiFi & low & high & medium & medium & low & high \\
\hline WiMAX & low & very high & high & high & very high & high \\
\hline $\begin{array}{c}\text { Mobile } \\
\text { communication }\end{array}$ & low & high & high & high & medium & very low \\
\hline
\end{tabular}

Therefore, EE solutions have become crucial. The summary of the proposed major existing energy-saving mechanisms is as follows: (i) radio optimization techniques (transmission power control [21,22], cooperative communication [23,24], and modulation optimization [25,26]); (ii) sleep/wakeup schemes (topology control [27,28], and duty cycling schemes [29-31]); (iii) energy harvesting and wireless charging (utilizing energy harvesting [32-34], and wireless charging [35-37]); (iv) energy-efficient routing and WSN's architecture (cluster architectures [38,39], multipath routing [40,41], and relay node placement [42-44]); and (v) data reduction mechanisms (aggregation [45], adaptive sampling [29], compression [46], and network coding [47]). The summarised taxonomy of green WSNs is given in Figure 2. In the following sections, a detailed discussion on the existing energy-saving mechanisms is presented. 


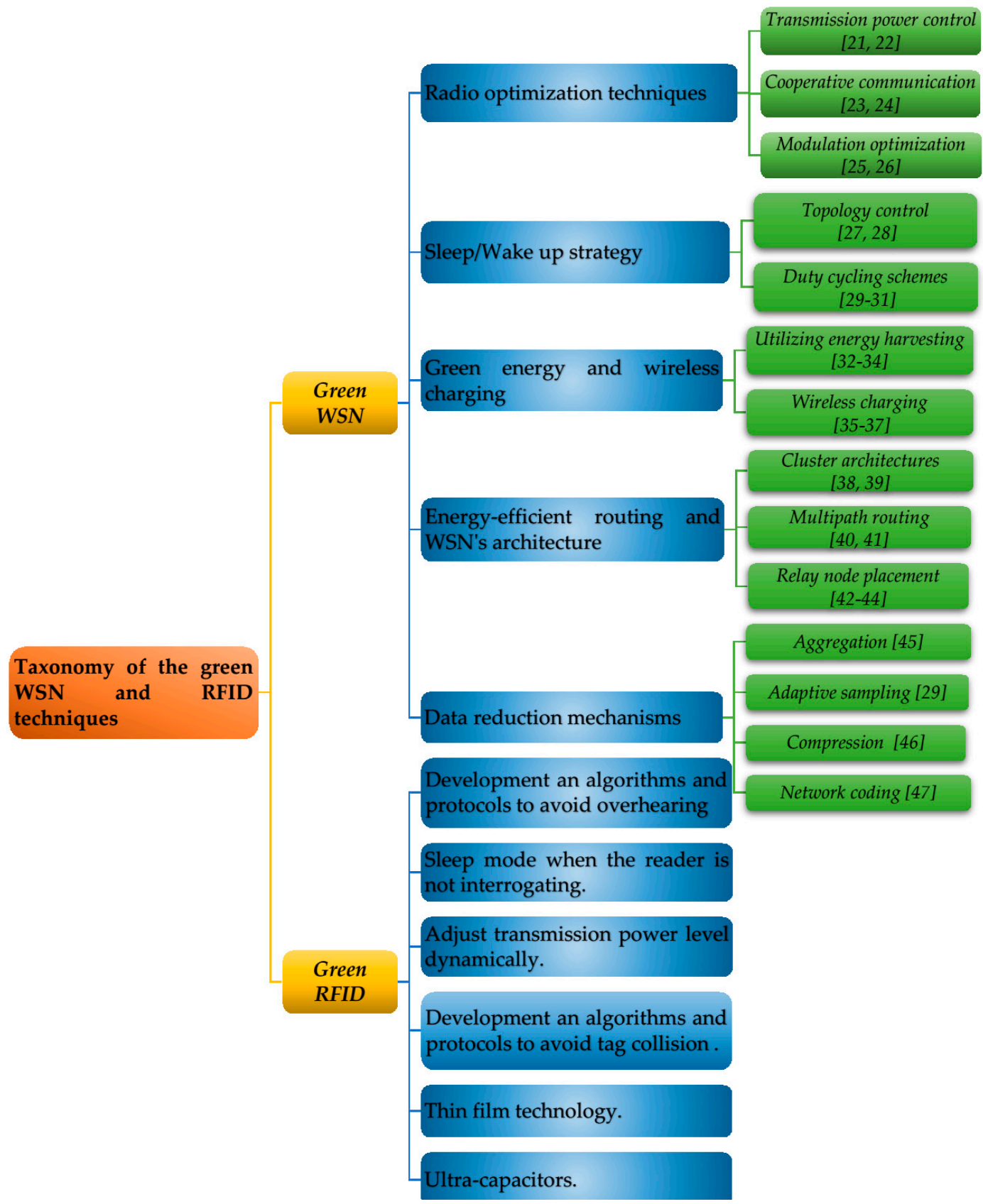

Figure 2. Summarised taxonomy of energy-saving techniques for green WSNs and RFID.

\subsection{Radio Optimisation Techniques}

The radio unit is the most pronounced energy consumption unit in the WSN. The energy depletion by the radio unit is caused by two parts: (i) powering the circuit, and (ii) powering of the transmitted signal. Short distances utilize more energy in powering the circuit, while powering the transmitted signal in long range communication consumes more power. Several references $[22,48]$ have investigated the strategies to enhance EE by adjusting transmission power level dynamically. In addition, the authors in [21] proposed advance saving energy cooperative topology, in which sensor nodes with higher remaining energy is at liberty to increase transmitting power leading to other nodes to decrease their own transmitting power. Moreover, the proposed topology reduces interference and improves connectivity due to the decrease in transmission power. However, an increase in delay potentials is expected, because more hops will be required for packet forwarding. Nevertheless, the problem of delay can be overcome through cooperative communications among the neighbouring sensor nodes, 
which creates a virtual multiple-antenna environment (spatial diversity). Virtual multiple-antenna reduces data retransmission, effectively improving the quality of the received signal by overcoming multi-path fading and shadowing phenomenon. References [49] and [50] extended the communication range among the sensor nodes as well as higher energy conservation and lower end-to-end (E-2-E) delays over certain broadcasting coverage as reported by Cui et al. [23]. Jayaweera [24], compared the energy consumption of both Single Input Single Output and virtual multiple-antenna (Multiple Input and Multiple Output) systems and showed that virtual multiple-antenna systems can provide higher energy savings and minimize E-2-E delays over certain propagation range distances. On the other hand, Cui et al. [25] examined the relationship among the energy consumption, transmission time, and bit error rate. The results showed that optimising the transmission time could have minimised the energy utilization needed to attain a stated bit error rate as well as delay requirement. Moreover, the authors in [26] presented a comparative study on the EE of three modulation techniques to select the optimal modulation scheme that yields the lowest energy utilization with various distances between nodes. To address the problem of joint transmission power and rate allocation in the uplink of a cellular wireless network, several works have considered transmission power and rate allocation. The two basic approaches that have been proposed in the recent literature are explained below.

- Joint rate and power control are modelled as two distinct games (i.e., an uplink transmission rate allocation and an uplink transmission power allocation problem), which are based on the game theoretic perspective. Users determine first their uplink transmission rate and then given their uplink transmission rate, they apply power control to allocate their uplink transmission powers [51,52]. The main drawback of this approach is that the optimisation problem is solved asynchronously and separately considering the two systems' resources. Thus, the combined outcome of the two distinct optimisation problems is less efficient than jointly solving the problem [53].

- The joint rate and power control problem is amended in a single-variable problem of the ratio of uplink transmission rate to the uplink transmission power [54]. However, this approach is limited in realistic cases and can only be applied in specific studies where simplified forms of utility functions are assumed (i.e., where the ratio of uplink transmission rate to power appears). As a result, the use of this approach strongly depends on problem formulation. The single variable problem is solved with respect to the substituted ratio. To determine users' optimal pair of uplink transmission rate and power, the maximum value of one resource is assumed and the other one is determined, so the ratio is equal to the optimal one. Although users update their uplink transmission rate and power in the same step, the obtained solution remains inferior compared with the corresponding solution of the actual joint two-variable optimisation problem discussed in [53].

Tsiropoulou et al. [53] proposed a novel utility-based game theoretic framework to address the problem of joint transmission power and rate allocation in the uplink of a cellular wireless network. Initially, each user is associated with a generic utility function that can properly express and represent mobile users' degree of satisfaction in relation to the allocated system's resources for heterogeneous services with various transmission rates. Then, a joint utility-based uplink power and rate allocation (JUPRA) game is formulated, where each user selfishly aims to maximise his/her utility-based performance under the imposed physical limitations, and its unique Nash equilibrium is determined with respect to both variables (i.e., uplink transmission power and rate). The JUPRA game's convergence to its unique Nash equilibrium is proven, and a distributed, iterative and low-complex algorithm for computing JUPRA game's equilibrium is introduced. The results showed the superiority of the proposed framework over other various state-of-the-art approaches. 


\subsection{Sleep/Wake Up Techniques}

Switching off (sleep mode) the non-active transceivers have become the ultimate approach towards the realization of EE in Information and communications technology, due to the fact that it can save large amount of energy. The philosophy behind the proposed approach is to exploit dense and redundant deployment of sensor nodes, leading to a small coverage area. The sensor nodes' off/on switching approach is more desirable for improving WSN EE and prolonging the battery lifetime of the wireless sensors. However, the coverage issue should be considered, and it should be guaranteed by the remaining active nodes. Misra et al. [27] proposed a subset solution in which nodes with minimum overlap areas are activated and must be capable of reducing network energy. Meanwhile, Karasabun et al. [28] modelled the EE issue as a subset selection problem of active connected sensors for correlated data payload gathering. Using spatial correlation, the sensor information of non-active sensor nodes can be obtained from those of active nodes, which makes it a good strategy. Equation (1) gives the average power consumption as the sleep power multiplied by the percentage of duration the system is in sleep mode plus the active power multiplied by the percentage of duration the system is in active mode all divided by 100. In a situation in which the system is designed to have bigger sleep energy comparable to the active energy, it is then feasible to engage power reduction strategy by tuning the sensor node to its lowest power mode. There are two scenarios in which the active power term can be larger than the sleep power term either (i) the power ratio per event is large or (ii) active power events have higher frequency.

$$
P_{\text {avg }}=\frac{\left(P_{\text {sleep }} \times \% \text { time asleep }\right)+\left(P_{\text {active }} \times \% \text { time active }\right)}{100}
$$

On the other hand, one can exploit the duty cycling schemes to make a sensor node switched on/off based on network activity (traffic conditions). Duty cycling schemes can be classified into three categories: on-demand, asynchronous, and scheduled rendezvous. Meanwhile, duty cycle-based protocols are certainly the most EE [29,30]. However, it should be taken into account that the low duty cycle has the capability to conserve a large big volume of energy but can lead to high communication delays. To reduce the delay, the protocol parameters can be tuned before deployment for ease, although it may result in inflexibility, or dynamical settings can be deployed to reflect the instantaneous traffic conditions. Moreover, the active period of nodes in order to optimise power consumption is a function of the traffic load, buffer overflows, delay requirements or harvested energy are discussed in [31].

\subsection{Energy Harvesting and Wireless Charging Techniques}

Key features of wireless sensors energy source such as sustainability and reliability, as well as reduction of greenhouse gas emissions can be met through advances in renewable energy technology [55]. Moreover, the renewable energy technology is one of the promising ways to address the EE issue of WSN located in rural and remote areas. In this terrain profile, it is difficult to replace batteries due to geographical limitations (challenging terrain), which makes access to these sites difficult [32]. The solar cells have low maintenance needs and high reliability, with an expected life span of 20-30 years. Additionally, new sensor technologies have emerged that harness power from their immediate environments, such as wind and kinetic energy [33]. The harvested energy is then converted to electrical signals, which are either consumed directly or stored for later usage. For example, using solar panels to charge a rechargeable battery during daytime. At night, nodes switch to conservative mode drawing energy from the stored power. During the protocol design stage, consideration must be given to uneven residual energy distribution, which is the difference in the quantity of energy collected [34]. In a case that there is no power to harness, battery life cycle capacity is formulated to calculate whether 
its total storing capability referenced to the magnitude of charge/discharge cycles, stated as depth-of discharge (DoD), is enough for the job. The life cycle capacity is estimated as:

Life cycle capacity $=$ Rated battery capacity $\times$ Rated charge_discharge cycle life $\times$ DoD

For example, for the ML1220 rechargeable coin cell, the rated capacity is $17 \mathrm{mAh}$, charge_discharge cycles is 1000 cycles, and DoD is $10 \%$; thus life cycle capacity $=17 \mathrm{mAh} \times 1000$ cycles $\times 10 \%$ per cycle $=1.7 \mathrm{Ah}$.

Renewable energy technology is associated with energy estimation schemes for astute energy management. Thus, there is the need to undertake inept energy-saving mechanisms in addition to renewable energy technology in order to attain a high reliability status. The sensors may incorporate dynamic behaviour tendencies in the face of the estimated energy not been able to sustain them in the next recharge cycle. Hence, they can optimise decisive parameters such as sampling rate, transmit power and duty cycling to adapt their power consumption according to the periodicity and magnitude of the harvestable source. On the other hand, it is justifiable to allocate sensor nodes with large residual power with bigger sleep duration and shorter RF range, whereas, those with bigger residual power are selected as the preferable routing route [56]. However, efforts have not been made to develop protocols assuming battery degradation over time (leakage, storage loss), which will impact WSN performance.

The attributes and operations of the renewable energy sources available in outdoor environmental conditions are very different from those found in indoor industrial and commercial environments. Table 3 shows a summary of the indoor and outdoor energy sources and their characteristics.

Table 3. Summary of the indoor and outdoor energy harvesting and characteristics.

\begin{tabular}{ccccc}
\hline \multirow{2}{*}{ Environment } & Solar Panel & Wind Generator & Thermoelectric & Electromagnetic \\
\cline { 2 - 5 } & $100 \mu \mathrm{W} / \mathrm{cm}^{2}$ & $\begin{array}{c}35 \mu W / \mathrm{cm}^{2} @ \text { wind } \\
\text { speed }<1 \mathrm{~m} / \mathrm{s}\end{array}$ & $100 \mu \mathrm{W} / \mathrm{cm}^{2} @ 5{ }^{\circ} \mathrm{C}$ & $\begin{array}{c}4 \mu \mathrm{W} / \mathrm{cm}^{3} @ \text { human } \\
\mathrm{motion}(\mathrm{Hz})\end{array}$ \\
\hline $\begin{array}{l}\text { Power density of the } \\
\text { indoor environment }\end{array}$ & $\begin{array}{c}3.5 \mathrm{~mW} / \mathrm{cm}^{2} @ \text { wind } \\
\text { speed } \leq 8.4 \mathrm{~m} / \mathrm{s}\end{array}$ & $3.5 \mathrm{~mW} / \mathrm{cm}^{2} @ 30^{\circ} \mathrm{C}$ & $\begin{array}{c}800 \mu W / \mathrm{cm}^{3} @ \\
\text { machine }(\mathrm{kHz})\end{array}$ \\
$\begin{array}{l}\text { Power density of the } \\
\text { outdoor environment }\end{array}$ & $10 \mathrm{~mW} / \mathrm{cm}^{2}$ & \begin{tabular}{l} 
such \\
\hline
\end{tabular}
\end{tabular}

Given the wide spectrum of IoT device formats, applications, and use cases to choose from, it is nearly impossible to authenticate with assurance that a given device will make good a IoT energy harvesting device without prior knowledge of application specifics and system operations. This notwithstanding, some indices are available to grade some devices as likely energy harvesting devices or otherwise. Inspiration can be drawn from the viewpoint of cost-effectiveness and technical standpoint. Table 4 is a sample IoT devices/applications and their suitability for use with energy harvesting sources in South Korea.

The evolution of wireless power charging technology has made it possible for energy constraint devices to maintain functionality in a more controllable manner, thus increasing the sustainability and reliability of WSNs [17]. Today, we can see that the wireless power charging concept has already been applied in numerous applications, such as power medical sensors and implantable devices [57], to restock sensors embedded in concrete wall [58], and to power a ground sensor from an unmanned aerial vehicle [59]. Generally, energy transfer techniques can be classified into (i) non-radiative coupling-based charging, which can be classified into three techniques: magnetic inductive coupling [60], magnetic resonance coupling [61], and capacitive coupling [62]; and (ii) radiative RF-based charging, which can be classified into two techniques: directive RF power beamforming and non-directive RF power transfer [63]. However, in capacitive coupling, the achievable amount of coupling capacitance is dependent on the available area of the device [64]. Nevertheless, for a typical-sized portable electronic device, it is hard to generate sufficient power density for charging, which imposes a challenging design limitation. As for directive RF power beamforming, the limitation lies in fact that the charger needs to know the exact location of the energy 
receiver [65]. Due to the obvious limitation of above two techniques, wireless charging is usually realized through three other techniques: magnetic inductive coupling, magnetic resonance coupling, and non-directive RF radiation [16].

Table 4. IoT devices/applications and their suitability for use with energy harvesting sources.

\begin{tabular}{|c|c|c|c|c|c|}
\hline \multirow{2}{*}{\multicolumn{2}{|c|}{ IoT Applications }} & \multicolumn{4}{|c|}{ Energy Harvesting Source } \\
\hline & & Solar Panel & Wind Generator & Electromagnetic & Thermoelectric \\
\hline \multirow{6}{*}{ Smart Home } & Outdoor sensor & $\checkmark$ & $\checkmark$ & $\checkmark$ & \\
\hline & Smart thermostat & $\checkmark$ & $\checkmark$ & & \\
\hline & Air quality monitor & $\checkmark$ & $\checkmark$ & & \\
\hline & Lighting & $\checkmark$ & & $\boldsymbol{v}$ & \\
\hline & Security monitor & $\checkmark$ & & & \\
\hline & Smart door lock & $\checkmark$ & & & \\
\hline \multirow{2}{*}{ Wearables } & Smartwatch & $\checkmark$ & & & \\
\hline & Monitoring and tracking & $\checkmark$ & & & \\
\hline \multirow{2}{*}{ Health } & Medical patch & $\checkmark$ & & $\checkmark$ & \\
\hline & Fitness band/monitor & $\checkmark$ & & & \\
\hline \multirow{2}{*}{ Industrial } & Factory automation & $\checkmark$ & $\checkmark$ & & $\checkmark$ \\
\hline & Machine monitor & $\checkmark$ & & & $\checkmark$ \\
\hline Vehicles & Wireless parking meter & $\checkmark$ & $\checkmark$ & & \\
\hline
\end{tabular}

In non-directive $\mathrm{RF}$ radiation schemes, electric energy is sent as an electromagnetic radiation within the RF spectrum of $300 \mathrm{GHz}$ and $3 \mathrm{kHz}$ [66]. RF energy transfer is suitable for far-field communications. Experiences have indicated that RF power transfer has poor RF-to-DC energy conversion efficiency when confronted with RF harvested power. Detailed information on this subject is presented in $[67,68]$. Using Maxwell's equation, electric current is initially generated from a magnetic coupling that is tuned to resonate at the centre frequency [69]. Electric energy is then transported through the magnetic field. Lastly, magnetic resonance coupling is generated by an evanescent field, which generates and sends electrical energy between two resonators [61]. To attain this type of resonator, a capacitance is inserted between an induction coil. Inductive and magnetic resonance coupling techniques are classified as short-range communications, also known as near-field wireless communications (NFC) [70]. Near-field wireless transmission is characterised by high power conversion efficiency, which is dependent on the coupling coefficient and the distance between two coils/resonators. The operating range (distance between transmitter and receiver) is a major challenge for near-field wireless transmissions because power rapidly decreases as the distance between devices increases (i.e., inverse square law) [71]. The advantages, disadvantages, and effective charging distance of these three techniques are summarised in Table 5.

Wireless energy delivery to deployed sensor nodes have been investigated in several studies [35-37]. Wireless energy delivery is a new frontier that must be explored by wireless charging technologies, because it creates the environment in which sensor nodes are able to share energy between neighbours. Therefore, in the nearest future, wireless networks nodes are envisioned to incorporate energy sharing scheme by harvesting energy from the environment and transfer some of these energy to other sensor nodes, making a self-sustaining network [72]. To realise this paradigm, multi-hop energy harvesting techniques have been studied [68], thus opening a new dimension in the development of wireless charging protocols and energy cooperative systems, as well as energy-efficient routing. 
Table 5. Summary of the advantages, disadvantages, and effective charging distance of the energy transfer techniques.

\begin{tabular}{|c|c|c|c|}
\hline Technique & Advantages & Disadvantages & Charging Distance \\
\hline $\begin{array}{l}\text { Magnetic inductive } \\
\text { coupling }\end{array}$ & $\begin{array}{l}\text { - Simple implementation. } \\
\text { - } \quad \text { Safe for human. }\end{array}$ & $\begin{array}{l}\text { - Short charging distance. } \\
\text { - Needs tight alignment } \\
\text { between chargers and } \\
\text { charging devices. } \\
\text { - Heating effect. }\end{array}$ & $\begin{array}{l}\text { From a few millimetres } \\
\text { to a few centimeters. }\end{array}$ \\
\hline $\begin{array}{l}\text { Magnetic resonance } \\
\text { coupling }\end{array}$ & $\begin{array}{l}\text { - } \quad \text { Loose alignment. } \\
\text { - } \quad \text { Chanline-of-sight charging. } \\
\text { simultaneously on } \\
\text { different power. } \\
\text { - } \quad \text { High charging efficiency. }\end{array}$ & $\begin{array}{l}\text { - } \quad \text { Limited charging distance. } \\
\text { - } \quad \text { Complex implementation. }\end{array}$ & $\begin{array}{l}\text { From a few centimeters } \\
\text { to a few meters. }\end{array}$ \\
\hline $\begin{array}{l}\text { Non-directive RF } \\
\text { radiation }\end{array}$ & $\begin{array}{l}\text { Long effective } \\
\text { charging distance. }\end{array}$ & $\begin{array}{l}\text { - } \quad \text { Line of-sight charging. } \\
\text { - } \quad \text { Low charging efficiency. } \\
\text { Not safe when the RF } \\
\text { density exposure is high. }\end{array}$ & $\begin{array}{l}\text { Typically, within several } \\
\text { tens of meters, up to } \\
\text { several kilometers. } \\
\text { Suitable for mobile } \\
\text { applications. }\end{array}$ \\
\hline
\end{tabular}

Simultaneous Wireless Information and Power Transfer (SWIPT) is a technique that can reduce the total recharging cost to enhance the lifespan of WSNs. The concept of SWIPT was first introduced in [73]. SWIPT has recently attracted attention in the field of wireless communication networks $[66,74,75]$. In the era of 5G communication, SWIPT technology could be fundamentally important for energy and information transmissions within numerous types of modern communications networks.

In WSNs, power usage is usually divided into three parts [76]: sensing, data processing and communication. Among the three, communication is the most costly function in a typical sensor node [77]. Hence, local data processing is important to minimise the power utilisation of WSNs because the failure of any node can re-route the structure. In addition, robust communication protocols are critical to efficiently exploit energy sources. Peer et al. [78] proposed a hybrid TS and PS spectrum sharing protocol for $\mathrm{EH}$ wireless sensor nodes. However, communication protocols must be further investigated to offer an optimal self-sustainable solution. Moreover, clustered WSNs with SWIPT that re-charge low energy relay nodes in cooperative clustered WSNs have been considered in [79], in which the authors considered a WSN consisting of multiple clusters of sensors and a sink node that collects data from the sensors in the clusters. To enable SWIPT, the head node of each cluster works as an information and power transferred. Relay node receiver harvests the RF energy from the head node of the cluster and recharges the batteries. Guo et al. [79] proposed a distributed iteration algorithm with closed-form transmission power, PS ratio and relay selection by utilising decomposition. Tong et al. [80] focused on the development of network deployment and its routing strategy. The idea is to reduce the total recharging cost to enhance the lifespan of WSNs. An optimisation problem is formulated using joint network deployment and routing in [81] by assuming that the sensors can be continuously recharged before their power source is exhausted and by obtaining complete knowledge of CSI. A few prototype implementations of sensor nodes are investigated in [81] and [82]. By reaping the benefits of SWIPT, low power WSNs deployed in the health care sector can recharge power sources while in operation, thereby improving the QoE [83]. Certain works have suggested using a wireless energy charger application for WSNs because it supports mobility $[84,85]$. A practical, real-time wireless recharging protocol for dynamic wireless recharging in sensor networks is proposed in [86]. The real-time recharging framework supports single or multiple mobile vehicles. Similarly, a collaborative wireless charging scheme has been presented in [87]. Recharging selected nodes in remote areas by using unmanned aerial vehicles can address the issue of recharging a single node. Johnson et al. [88] simulated a limited recharging system and verified the effectiveness of recharging a single node. However, their work does not describe a robust system model and is limited to simulations. A 
prototype-based implementation for similar EH architectures is provided in [89]. Further research must be conducted to select a proper energy storage mechanism, which is directly related to efficiency and long operational lifetime of sensors.

\subsection{Energy-Efficient Routing and WSN Architecture}

Generally, designing of single-path routing protocol is easier than a multipath routing protocol. The drawback of a single-path protocol is that it swiftly drenches the energy when selected as the path. Additionally, in scenarios where a single-path protocol node is out of energy, a fresh route must be recomputed. Meanwhile, multipath routing creates a platform to equally re-distribute the energy among the sensor nodes by rotating the forwarding nodes. These have the capacity to increase network reliability by provisioning multiple routes, speeding up network recovering rate from a failure. For readers interested in the multipath routing protocols for WSN, a comprehensive survey is given in [40]. In terms of the energy efficiency of the multipath routing protocols for WSN, the Energy-Efficient Multipath Routing Protocol (EEMRP), discussed in [41], focuses on discovering multiple node-disjointed paths based on a cost function driven by the energy levels and hop distances of the nodes, and subsequently allocates the traffic rate to each selected path. Moreover, Energy-Efficient and Collision Aware (EECA), discussed in [90], is proposed as a dual node disjointed and collision-free route considering source and sink. The results showed that the efficiency of the multipath routing protocols in terms of the energy are better than single-path routing protocols. Moreover, it is capable of further improving both the EE as well as lifetime of the WSN, if the routing algorithms are not only the function of the shortest paths, but consider the residual energy before selecting the next hop, as reported in [91]. Liu et al. [91] proposed dual novel energy-aware cost functions to improve the energy-balancing performance of the routing protocol by considering nodes in hotspots consumes more energy: (i) Exponential and Sine Cost Function-based Route (ESCFR) function, maps a miniscule variation in remaining nodal energy to a big variation in the cost function value. The idea of the ESCFR, operates by giving higher preference to sensor nodes having bigger remaining energy during route selection, thus creating energy equilibrium. (ii) The Double Cost Function-based Route (DCFR) protocol makes decisions by taking into consideration the energy consumption rate of nodes, as well as the residual energy, which enhances the energy-balancing performance of the routing protocol, even in networks facing obstructions. Unfortunately, the location of the sensor nodes may deplete energy in a given region or create energy holes. However, optimal sensor node placement via uniform distribution or by including a few sensor relay nodes with enhanced capabilities can be deployed to address the issue. Generally, this leads to energy balance improvement among the sensor nodes, avoiding hot-spots sensor nodes and guarantee RF coverage and link connectivity [92]. Plethora of research have focussed on locating the least number of sensor relay nodes or optimal sensor relay placement that will extend the network lifetime [42-44]. Meanwhile, other studies have proposed a cluster architecture approach, which organizes the sensor nodes into clusters. The motive of this approach is dependent on the cooperation among sensor nodes in the same cluster. Meanwile, each cluster is managed by a selected node known as the cluster head, which is responsible for coordinating the members' activities and communicating with other cluster heads or the base station [38,39]. Cluster architectures is one of the most desirable approaches to improving the EE of the WSN. Cluster architecture comes with many benefits, such as: improvement in WSN energy-efficiency and network scalability by maintaining a hierarchy in the network. To fully derive these benefits, these strategies must be considered:

i. Reduction of transmitting distance of cluster members requiring lower transmission power.

ii. Cluster heads limiting the transmissions frequency as a result of fusion.

iii. Mandating the cluster head to perform all the energy-sapping functions, such as coordination and aggregation.

iv. Permit to power-off some cluster members while the cluster head assumes the forwarding roles.

v. Alternate the choice of cluster head among the nodes so as energy consumption in the network. 


\subsection{Aggregation and Reduction of the Data}

Obviously, data transmission and processing are not cheap with reference to energy consumption. Therefore, efficiency in handling data delivered to the sink nodes leads to energy saving. Reducing and aggregating the data quantity being delivered to the sink nodes are considered efficient solutions to increase EE during the transmission process [17]. In data aggregation schemes [45], nodes are permitted to only re-transmit the average or the lesser of the received information. However, information aggregation may lead to latency reduction since traffic is reduced, thereby reducing network delays. The drawback of this approach is that it may impact negatively on the accuracy of the data collected. If an optimal aggregation function is not deployed, it may become difficult to recover the original data sent to the sink [46]. Therefore, it is not recommended to use this technique with applications that need high accuracy; but adaptive sampling techniques are used when the criteria are formed in terms of coverage or information precision. In adaptive sampling approaches, the sampling rate are adjusted at each sensor and at the same time, making sure that the application requirements are achieved referenced to range or data precision. For instance, in a supervision task, low-power acoustic sensors can be deployed to notice an imposition. In a scenario where an event is stated, power-hungry cameras can be instructed to gather better-grained information [29]. Three-dimensional correlation is a good candidate for reducing the sampling rate in areas experiencing low variation in sensed data. In human activity recognition applications, Yan et al. [93] suggested that that sampling acquisition be based on core user activity, rather than taking samples in all unnecessary instances such as sitting, jumping, biking or running. Conversely, network coding can be deployed to reduce the overall data traffic in broadcast environment by transmitting a linear aggregation of several packets rather than a copy of each packet. Between computation and communications, communications utilize lesser energy because computations are generally regarded as power hungry application as a result, network coding exploits this gain. Wang et al. [47] fuse network coding and connected dominating sets to additionally decrease energy utilization in broadcast events. AdapCode [94] is an information broadcasting protocol designed by allowing a node to broadcast $N$ messages received at several other nodes, resulting in energy conservation. The resultant energy savings from the bandwidth is $(N-1) / N$ compared to naive flooding. The receiver node can recover the original packets by Gaussian elimination after receiving $N$ coded packets successfully. Moreover, AdapCode enhances reliability by adjusting $N$ to the sensor node numbers, because when $N$ rises and the number declines, the packets recovery rate for data decoding decreases. Reliability can be further improved by permitting more sensor nodes to acquire less than $N$ packets and send a negative acknowledgement to recover loss information.

\section{Green Radio-Frequency Identification}

The RFID system consists of RFID tags with a unique identifier electronic product code (EPC), an RFID reader, and middleware [95]. For an object to be tracked by an RFID enabled system, RFID tags must be appended to the target object. The design nomenclature of RFID tags consists of a small microchip linked to an antenna. As with other wireless devices, the antenna is responsible for transmitting and receiving of the radio signals. It is not necessary compulsory that RFID tags must be direct line of sight with the RFID reader. RFID tags can be read utilizing non-line of sight technology. Boasted by the memory capacity, the EPC and other valuable data can be read and traced using RFID readers effortlessly. An RFID reader can be considered as the base station (BS) or access point of the system and it is responsible for energizing, sending data and commands to connect RFID tags attached on a fixed or mobile object [96]. Meanwhile, RFID systems is characterized as having very low (i.e., a few meters) RF coverage. Some of the notable spectrum bandwidths of interest are very low frequencies (VLF) at 124-135 kHz up to ultrahigh frequencies (UHF) at 860-960 MHz [16].

RFID tags can be classified into two types in terms of power source: (i) Active RFID tags have a local power source (battery) and operate hundreds of meters from the RFID reader. (ii) Passive RFID tags are without batteries and collect energy from a nearby RFID reader's interrogating radio waves by means of the principle of induction. Thus, the EE is a key requirement for the wider acceptance 
of the active RFID systems that utilize battery-constrained tags. Additionally, active RFID is less advantageous than passive RFID in terms of its tag cost and size, but more advantageous in terms of sensing distance, sensing rate, and stability [16,97]. Semi-passive tags are a third variant of RFID, and they are equipped with batteries; however, these batteries are not an integral part of RF transmission. Hence, they are not considered active RFID tags.

\subsection{Passive RFID Systems}

Passive RFID tags lack an inbuilt energy source; they are powered by the electromagnetic energy emitted from an RFID reader instead. Passive RFID tags are popular in several applications, such as access control, file tracking, race timing, supply chain management and smart labels. The cheap price of RFID tags allows their wide deployment across a wide spectrum of the industry. RFIDs have already been promoted as the most cost-effective solution with satisfactory achievements in smart parking systems [98]. RFID in smart parking systems have mainly been used for check-ins and check-outs of passing vehicles in parking areas; such vehicles are equipped with e-pass cards with active RFID tags [99]. Each vehicle that enters a parking area has a unique identification number that can be paired with its license plate. The barriers only open if the vehicle is recognised as being registered. Moreover, the authors in [100] combined RFID technology with wireless sensors to collect information on the occupancy state of parking spaces and direct drivers to the nearest vacant parking lot. Other for vehicle validation at the entrance and exit of a parking area, RFID technology has been utilised for parked vehicle localisation by exploiting the time difference of arrival and the received signal strength measurements [101]. Furthermore, the authors in [102] presented an analysis and evaluation of a passive RFID-based framework in the context of smart parking systems. The main novelty of the proposed framework is the adoption of RFID tag-to-tag communication, which can support a more energy-efficient collection of information than the conventional direct type of communication. The overall framework is considered and examined within a smart parking system use case scenario, in which RFID technology is adopted for: (a) vehicle validation when entering and exiting the parking area; (b) identification and localisation of parked vehicles; and (c) smart parking space management. The superiority of the proposed framework over conventional direct RFID reader tag communication is demonstrated in terms of: (i) the reduction of RFID readers' transmission power to the required minimum to guarantee connectivity, and (ii) the expansion of RFID readers' coverage areas to communicate with many distant tags. A summary of the passive RFID system is given in Figure 3.

Electromagnetic energy transfer techniques can be classified into three main techniques: (i) RF energy harvesting, (ii) inductive coupling, and (iii) magnetic resonance coupling (Table 5). Passive RFID system energy transfer techniques are NFC, either inductive coupling or backscatter. The RFID reader emits a sinusoidal signal. The tag antenna is tuned to receive the signal from the reader. The internal IC of the passive tag contains a rectifier circuit that converts the power into DC, enabling the tag circuitry to work. The circuitry modulates the signal to an extent and then returns it to the reader. During this process, the tag does not create a separate signal; it merely modulates the signal received from the reader. An explanation of the backscattering principle is given in detail in [96].

The Passive RFID tag feature is low power consumption, making it a suitable candidate in wireless sensing applications. However, operating coverage distance is a notable challenge. In best case scenario, the maximum RF coverage distance of passive tags are up to $7-15 \mathrm{~m}$. The reason for this is that the system is powered using electromagnetic induction, which is itself relatively weak. Additionally, path loss, which is considered to be one of the most important parameters in any wireless communication, must be included. Accordingly, path loss is a crucial design parameter in RFID transmission. Path loss is due to many effects, such as free-space loss, refraction, scattering and diffraction, reflection, the height of antenna, the surrounding environment and weather (dry or moist air), the distance between the transmitter and the receiver, the height and location of antennas [95]. Thus, choice of calculation path loss model is a vital decision. In [103], the author discusses and compares more accurate path 
loss predicting models extensively, such as Friis's model, CCIR model, Hata model, etc., for different environments. However, these models have application-specific device operating frequencies. For more of clarity, we discuss, in the following, the relationship among distance, operating frequency, and path loss based on the most rudimentary mathematical model to calculate path loss, Free Space Path Loss (FSPL) model that can be written as follows:

$$
P_{F S P L}=\left(\frac{4 \pi f d}{c}\right)^{2}
$$

where $f$ and $c$ denote the operating frequency (in $\mathrm{Hz}$ ) and speed of light (in metres/second), respectively. Also, $\frac{f}{c}$ is called the signal wavelength $(\lambda)$. The term $d$ refers to the distance between the RFID reader and RFID tag antennas. $\lambda$ and $d$ are in the same unit of length (in metres). If $d>>\lambda$, it is assumed that both antennas are in the far field of each other. Equation (3) shows that the operating frequency is directly proportional to the square root of the path loss considering all other variables constant. In addition, the distance between the antennas is also directly proportional to the square root of the path loss considering all other variables constant including the operating frequency, which means that the received signal power at RFID tag rapidly decreases with increasing transmit-receive distance, which also results in an increase in path losses.

The wake-up signals deployed in duty cycle leads to energy inefficiency as lots of energy are utilized. Low energy powered radios can be deployed to wake up a sensor node only when need arises, such as sending or receiving packets. Meanwhile, power-consuming transceivers are deployed for information transmission. Ba et al. [104] suggests a network consisting of non-active RFID wake-up transceiver called WISP-Motes and RFID readers. A non-active RFID wake-up transceiver utilizes the energy derived from the reader transmitter to initialize an interruption that awakens the node. In reality, it is impossible to equip all the sensor nodes with RFID readers because of its power-hungry capability. The aforementioned issue and the limited operational range have restricted passive RFID from being utilized as only as a single-hop scenario. Software simulations have indicated that WISP-Motes can conserve a greater quantity of energy at the cost of more hardware and magnified latency in information delivery. The authors showcase their advantages in the scenario of lightly delay-tolerant system mobile elements accompanied with RFID readers.

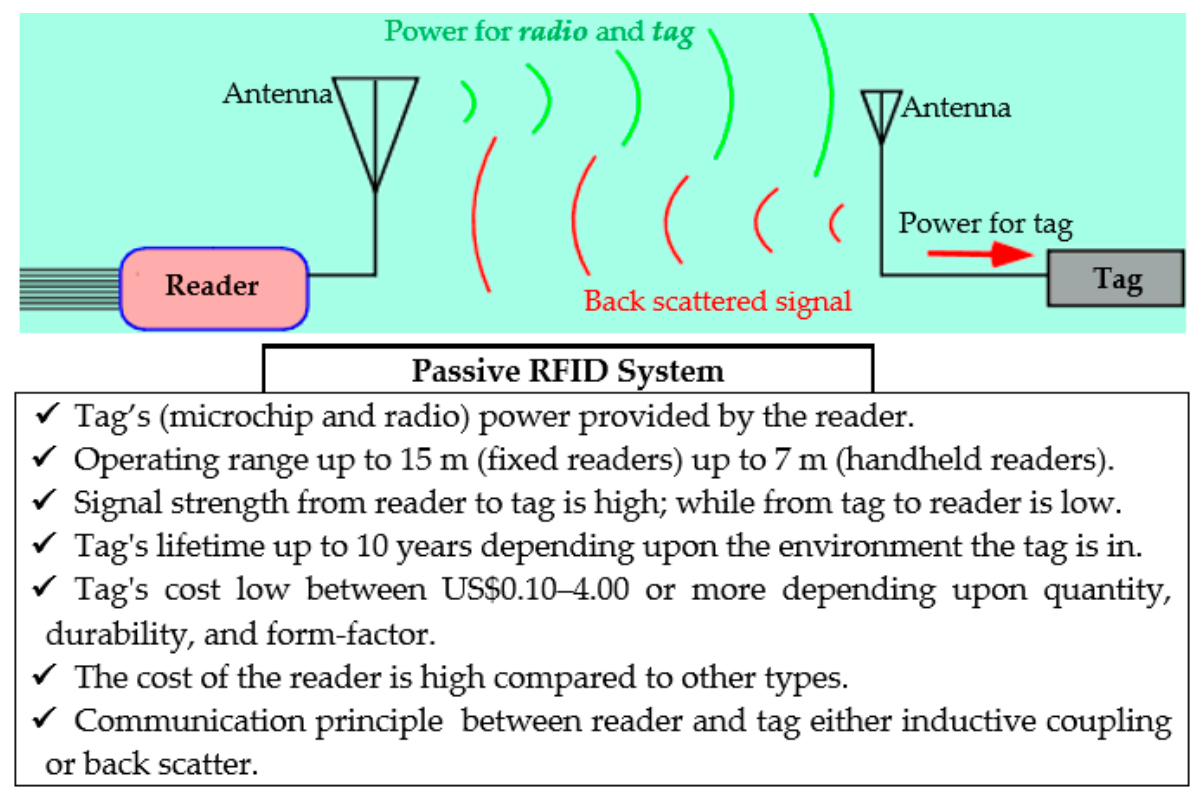

Figure 3. Passive RFID system. 


\subsection{Active RFID System}

A battery-assisted RFID tag that uninterruptedly broadcasts its signal is known as Active RFID. Active RFID tags are usually deployed as "beacons", which precisely trail the real-time position of targets or in high-speed settings such as tolling. Active tags which are battery powered have a greater reading range when compared to passive tags; however, they are also much costlier. A summary of the active RFID system is given in Figure 4.

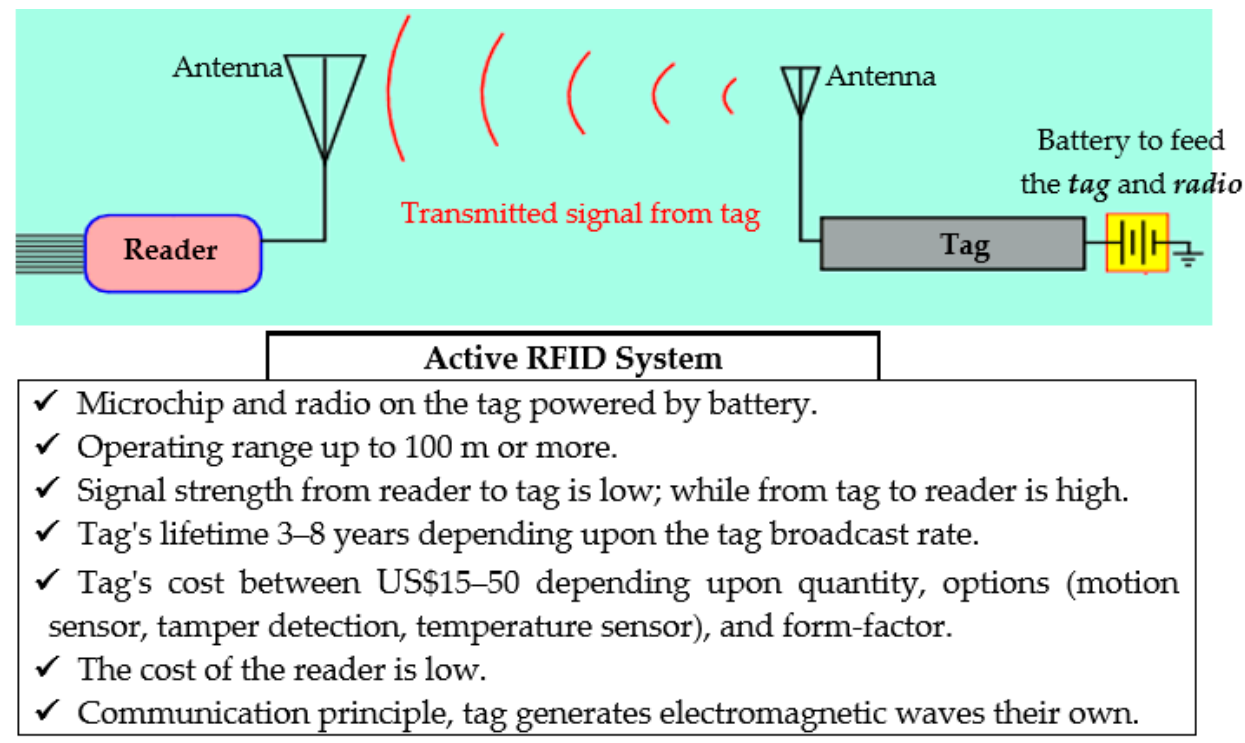

Figure 4. Active RFID system.

The most important issue when considering an active RFID system is the energy storage device. The batteries and capacitors are the two most common storage devices. A summary comparison for these two commonly storage devices are provided in Table 6.

Table 6. Comparison of the two most common storage devices.

\begin{tabular}{|c|c|c|}
\hline Issues & Battery & Capacitor \\
\hline Advantages & $\begin{array}{l}\text { - } \quad \text { High power density. } \\
\text { - } \quad \text { High energy density. } \\
\text { Easily replaceable in most cases. }\end{array}$ & $\begin{array}{l}\text { - High power density. } \\
\text { Does not loose ability to retain power } \\
\text { with time. }\end{array}$ \\
\hline Challenges & $\begin{array}{l}\text { - } \quad \text { Poor to "form factor". } \\
\text { - } \text { pechargeable form loses ability to retain } \\
\text { - Have to be replaced periodically, and } \\
\text { difficult to replace in larger numbers } \\
\text { and some applications in remote areas. }\end{array}$ & $\begin{array}{l}\text { - } \quad \text { Low energy density. } \\
\text { - } \text { curceptible to damage with } \\
\text { - } \quad \text { Capacity is highlions. } \\
\text { - Harder to replace compared to batteries. }\end{array}$ \\
\hline Improvements & $\begin{array}{l}\text { Introduction of thin film technology has } \\
\text { removed the issues related to } \\
\text { form factor. } \\
\text { There are a range of new technologies } \\
\text { which could have been tested, from } \\
\text { lithium-ion varieties to } \\
\text { redox-flow batteries. }\end{array}$ & $\begin{array}{l}\text { Introduction of ultra-capacitors have } \\
\text { enables the best of both components } \\
\text { with high power and energy densities. } \\
\text { - Size of ultra-caps are also significantly } \\
\text { smaller than regular capacitors. }\end{array}$ \\
\hline
\end{tabular}

Batteries have been the most notable energy sources for countless devices since their invention, and are still the most used portable power source in the world [105]. However, the problem with 
batteries is that they have a limited lifespan. After this certain period, they have to be replaced. Even with rechargeable batteries, there is a certain period after which the energy retaining capabilities of the battery diminish considerably. Additionally, form factor morphology is another key parameter that is considered when choosing the right storage device for a particular use-case. However, the relationship between these two characteristics (capacity and form factor) is most often conflicting. As the size of the storage device rises, normally, the device size will become larger, and vice versa [106]. Taking the capacity and form factor issue into consideration, batteries are slowly becoming a less viable option for RFID environments. Consequently, a compromise is needed to maintain desirable battery design in terms of both practicality and size, in order to retain batteries as options as storage devices for use in RFID environments. Extensive research has been carried out by academic institutes and the industrial sector on how to make energy storage devices as small and flexible as possible while having ample capacity and lasting usability in an RFID tag environment. With the introduction of thin film technology, batteries are starting to adapt to form factors appropriate for usage in wireless sensors. The end-goal of this process is a system which will enable electronic devices fabricated in a paper-thin width range. Carmo et al. [107] describes a thin film battery scheme in conjunction with suitable option for thermo-electric micro-systems. They recommend a strategy for fabricating thin film solid-state rechargeable batteries. This affords a deeper analysis and evidence in support of the notion that it is ideal for applications involving settings where a thermal difference is evidently accessible, e.g., human body. The popularity of the thin film approach is again supported in [108]. The aforementioned paper provides a design of rechargeable battery in an RFID tag environment in great detail.

Capacitors are very effective components for storing energy. They are equipped with an inherent ability to hold energy instantaneously, thus making them the preferred device for energy storage purposes. Meanwhile, there is a direct proportionality between capacitor size and energy storing capacity; the capacity to hold energy greatly depends on the size of the capacitor. Evidently, bigger sized capacitors store more current than smaller sized devices. Capacitors are also prone to damage in the face of high current and voltage fluctuations, making them dependent on the deployed environment. There is an evolution towards the development of super-capacitors and ultra-capacitors that have the capacity to store greater amounts of current. When ultra-capacitors are integrated into rechargeable batteries, they provide both longevity and solidity to the rechargeable batteries. Ultra-capacitors can store current in many times the amount of conventional capacitors, and as a result have become the design choice of many researchers and industry players. These ultra-capacitors are optimally appropriate in power conversion electronics circuits, as shown in [109]. Hybrid models have also emerged in which two models are utilized rather than a single model. Such models have found application and deployment in solar-powered WSN nodes [110]. In [111], the authors proposed a model, named "Prometheus", involving the deployment of a hybrid method. In this configuration, a dual phase storage scheme is discussed, consisting of a super-capacitor in one phase and a lithium rechargeable battery in the second phase. This scheme is deployed as a safeguard for running a Berkley's Telos Mote from a PV solar panel system. The experimental results are encouraging, suggesting that this system can run for 43 years in an application having $1 \%$ load, and can last for 1 year with a $100 \%$ load value.

Powering the electronics embedded into a smart garment is essential for e-textiles. Regarding energy storage devices, batteries are accepted as one of the most important and efficient ways to establish electricity networks. However, other technologies can be used, such as super-capacitors, which can now achieve energy density levels that are comparable to lead-acid batteries. In addition, super-capacitors are environmentally friendly and offer high power density, fast charging/discharging speed, and a long lifecycle [112]. The requirements of batteries change significantly depending on the wearable energy consumption. Three different types of devices can be distinguished, depending on their power needs $[35,113,114]$ :

- Low-end devices. These devices are similar to traditional watches or pacemakers that can be powered for a long time (years) by button type batteries, given their low energy consumption (usually under $100 \mu \mathrm{W}$ ). 
- Mid-range devices. These devices consume an average of $500 \mathrm{~mW}$, considering their use of wireless communications transceivers. They usually last less than a day (often just several hours) when transmitting continuously, although certain technologies make use of sleep modes or periodic transmissions (e.g., BLE beacons) to last long. This kind of device requires bulkier batteries than low-end devices (e.g., AA or AAA batteries), making them less appropriate to be embedded into smart clothing.

- High-end devices. These are devices similar to smartphones or laptops that consume up to $50 \mathrm{~W}$. They usually utilise Li-ion batteries, which can be bulky and add weight to a garment.

Table 7 presents certain examples of wearable devices with their power consumption and the basic characteristics of the battery that they usually carry. The operating period of a battery is determined by its power requirements and energy density. Energy density is the amount of electrical energy stored in a battery in a given weight $(\mathrm{Wh} / \mathrm{kg})$. Moreover, the selection of energy storage devices depends on the type of applications. Recent research has revealed that hybrid models that use both components can achieve good results, considering their own capabilities.

Table 7. Examples of wearable devices and the basic characteristics of their batteries.

\begin{tabular}{|c|c|c|c|c|c|}
\hline Device & Power & Battery Type & Operating Period & Weight (g) & $\begin{array}{c}\text { Size } \\
(1 \times w \times h / d \times h, m m)\end{array}$ \\
\hline Watches & 3-10 $\mu \mathrm{W}$ & Silver oxide button & $1-2$ years & 2.4 & $11.6 \times 5.4$ \\
\hline Pacemakers & $25-80 \mu \mathrm{W}$ & Lithium button & $7-10$ years & 2.83 & $20 \times 3.2$ \\
\hline Hearing aids & N/A & $\begin{array}{l}\text { Zinc-mercury } \\
\text { oxide }\end{array}$ & 25-30 days & $0.3-1.85$ & $(5.8-11.6) \times(3.6-5.4)$ \\
\hline Digital clocks & $13 \mathrm{~mW}$ & Silver oxide button & $\begin{array}{l}6-10 \text { months } \\
6-12 \text { months }\end{array}$ & $15-25$ & $(5.8-11.8) \times(1.65-5.4)$ \\
\hline LEDs & $25-100 \mathrm{~mW}$ & Silver oxide button & $\begin{array}{l}\text { (depends on the usage } \\
\text { frequency) }\end{array}$ & $15-25$ & $(5.8-11.8) \times(1.65-5.4)$ \\
\hline Pedometers & $250 \mathrm{~mW}$ & Silver oxide button & $\begin{array}{l}1-2 \text { years } \\
\text { (depends on the usage } \\
\text { frequency) }\end{array}$ & $15-25$ & $(5.8-11.8) \times(1.65-5.4)$ \\
\hline Portable radio & $500 \mathrm{~mW}$ & AAA & $\begin{array}{l}\text { 3-6 months } \\
\text { (depends on the usage } \\
\text { frequency) }\end{array}$ & $8.5-11$ & $10.5 \times 44.5$ \\
\hline
\end{tabular}

On the other hand, references $[6,10,115,116]$ considered the transmission power issue. The sleep mode technique, when the reader is not interrogating, to achieve energy saving was proposed by [10]. The authors in [6] proposed an algorithm and protocol to avoid overheating when the reader is not interrogating, in order to achieve energy saving. Meanwhile, the authors in $[115,116]$ proposed an algorithm and protocol to avoid tag collision during the transmission. Meanwhile, reference $[22,48]$ proposed adjusting the transmission power level dynamically, which could achieve energy saving, but less than a sleep mode technique. Recall that the major driver of green technology is ecological and energy fears. Reduction in RFID tags size should be exploited, as there is a direct correlation between quantity of non-degradable substance deployed in their engineering (e.g., biodegradable RFID tags, printable RFID tags, paper-based RFID tags), since the RFID tags themselves are generally hard to reuse [97].

Security and privacy are major concerns for IoT deployment. Implementing security algorithms requires a substantial device processing. Along with security, we must investigate appropriate mechanisms that consider energy consumption and the required QoS. The potentials of energy-efficient and secure mechanisms remain in their infancy, thus encouraging extensive research and development in this area. IoT involves resource-constrained devices, such as RFID, sensor nodes and high-end data servers. Therefore, finding and exploiting trade-offs is important to provide security among heterogeneous devices in the green IoT paradigm. Tags are typically energy-constrained, thus limiting the implementation of complex security algorithms. Energy-depleted RFID tags are a source of potential attacks from intruders with malicious intent. Moreover, modifying the data in RFID tags is also a security threat. Therefore, a natural solution is to password-protect the memory in RFID tags. Doing so is a challenge from an energy consumption perspective, because cryptographic algorithms 
require a large amount of energy and battery (active tag). In this regard, several methods with low energy requirements have been recently proposed for these cryptographic solutions $[117,118]$. The authors in [119] developed a communication strategy where a tag periodically communicates its security status to the reader and is authenticated. The information exchange between tags and the reader is secured using AES encryption. In addition, they used a PUF and a power sensing circuit to identify malicious readers and tags. The concept of semi-active tags, in which an energy-depleted RFID tag can use neighbouring tags, is also introduced to communicate their security status and be authenticated by the reader. The authors in $[120,121]$ presented a technical survey research on privacy and security problems for RFID with the consideration of the energy case.

\section{Conclusions}

Green technologies play an important role in enabling energy-efficient IoT. This study has provided an overview of popular research topics on green WSNs and RFID, which are considered to be the two main pillars of IoT applications and cover recent industry developments. We initially provided a taxonomy of the energy-saving techniques for green WSNs and RFID. A detailed discussion of each technique was subsequently presented to pursue a vision of green WSNs and RFID. By considering energy consumption and the required QoS, we suggest conducting further research to select a proper energy storage mechanism that is directly related to efficiency and long operational lifetime.

Author Contributions: Conceptualization, M.H.A. and S.K.; As the first author, M.H.A. wrote the main parts and the first draft of this study; S.K. and N.K. revised the final version of the paper; Funding acquisition, S.K.

Funding: This research was funded by the Research Program through the National Research Foundation of Korea (NRF-2016R1D1A1B03934653, NRF-2019R1A2C1005920).

Conflicts of Interest: The authors declare that they have no competing interests.

\section{References}

1. Arshad, R.; Zahoor, S.; Shah, M.A.; Wahid, A.; Yu, H. Green IoT: An investigation on energy saving practices for 2020 and beyond. IEEE Access 2017, 5, 15667-15681. [CrossRef]

2. Al-Fuqaha, A.; Guizani, M.; Mohammadi, M.; Aledhari, M.; Ayyash, M. Internet of things: A survey on enabling technologies, protocols, and applications. IEEE Commun. Surv. Tutor. 2015, 17, 2347-2376. [CrossRef]

3. Zanella, A.; Bui, N.; Castellani, A.; Vangelista, L.; Zorzi, M. Internet of things for smart cities. IEEE Internet Things J. 2014, 1, 22-32. [CrossRef]

4. Almotiri, S.H.; Khan, M.A.; Alghamdi, M.A. Mobile Health (m-Health) System in the Context of IoT. In Proceedings of the 4th IEEE International Conference on in Future Internet of Things and Cloud Workshops (FiCloud), Vienna, Austria, 22-24 August 2016; pp. 39-42.

5. Alsharif, M.H.; Nordin, R. Evolution towards fifth generation (5G) wireless networks: Current trends and challenges in the deployment of millimetre wave, massive MIMO, and small cells. Telecommun. Syst. 2017, 64, 617-637. [CrossRef]

6. Lee, C.-S.; Kim, D.-H.; Kim, J.-D. An energy efficient active RFID protocol to avoid overhearing problem. IEEE Sens. J. 2014, 14, 15-24. [CrossRef]

7. Tsai, C.-W.; Lai, C.-F.; Chiang, M.-C.; Yang, L.T. Data mining for Internet of Things: A survey. IEEE Commun. Surv. Tutor. 2014, 16, 77-97. [CrossRef]

8. Mukherjee, A.; Paul, H.S.; Dey, S.; Banerjee, A. Angels for Distributed Analytics in IoT. In Proceedings of the IEEE World Forum on Internet of Things (WF-IoT), Seoul, Korea, 6-8 March 2014; pp. 565-570.

9. Gelenbe, E.; Caseau, Y. The impact of information technology on energy consumption and carbon emissions. Ubiquity 2015, 2015, 1. [CrossRef]

10. Shaikh, F.K.; Zeadally, S.; Exposito, E. Enabling technologies for green internet of things. IEEE Syst. J. 2017, 11, 983-994. [CrossRef]

11. Zhu, C.; Leung, V.C.; Shu, L.; Ngai, E.C.-H. Green internet of things for smart world. IEEE Access 2015, 3, 2151-2162. [CrossRef] 
12. Miorandi, D.; Sicari, S.; de Pellegrini, F.; Chlamtac, I. Internet of things: Vision, applications and research challenges. Ad Hoc Netw. 2012, 10, 1497-1516. [CrossRef]

13. Baliga, J.; Ayre, R.W.; Hinton, K.; Tucker, R.S. Green cloud computing: Balancing energy in processing, storage, and transport. Proc. IEEE 2011, 99, 149-167. [CrossRef]

14. Shaikh, F.K.; Zeadally, S. Energy harvesting in wireless sensor networks: A comprehensive review. Renew. Sustain. Energy Rev. 2016, 55, 1041-1054. [CrossRef]

15. Akkaya, K.; Guvenc, I.; Aygun, R.; Pala, N.; Kadri, A. IoT-Based Occupancy Monitoring Techniques for Energy-Efficient Smart Buildings. In Proceedings of the IEEE in Wireless Communications and Networking Conference Workshops (WCNCW), New Orleans, LA, USA, 9-12 March 2015; pp. 58-63.

16. Alsharif, M.H.; Nordin, R.; Abdullah, N.F.; Kelechi, A.H. How to make key $5 \mathrm{G}$ wireless technologies environmental friendly: A review. Trans. Emerg. Telecommun. Technol. 2018, 29, e3254. [CrossRef]

17. Rault, T.; Bouabdallah, A.; Challal, Y. Energy efficiency in wireless sensor networks: A top-down survey. Comput. Netw. 2014, 67, 104-122. [CrossRef]

18. Sinha, R.S.; Wei, Y.; Hwang, S.-H. A survey on LPWA technology: LoRa and NB-IoT. ICT Express 2017, 3, 14-21. [CrossRef]

19. Ahmed, N.; Rahman, H.; Hussain, M.I. A comparison of 802.11 ah and 802.15.4 for IoT. ICT Express 2016, 2, 100-102. [CrossRef]

20. Alsharif, M.H.; Nordin, R.; Ismail, M. Energy optimisation of hybrid off-grid system for remote telecommunication base station deployment in Malaysia. EURASIP J. Wirel. Commun. Netw. 2015, 2015, 1-15. [CrossRef]

21. Chu, X.; Sethu, H. Cooperative topology control with adaptation for improved lifetime in wireless sensor networks. Ad Hoc Netw. 2015, 30, 99-114. [CrossRef]

22. Lin, S.; Miao, F.; Zhang, J.; Zhou, G.; Gu, L.; He, T. ATPC: Adaptive transmission power control for wireless sensor networks. ACM Trans. Sens. Netw. (TOSN) 2016, 12, 6. [CrossRef]

23. Cui, S.; Goldsmith, A.J.; Bahai, A. Energy-efficiency of MIMO and cooperative MIMO techniques in sensor networks. IEEE J. Sel. Areas Commun. 2004, 22, 1089-1098. [CrossRef]

24. Jayaweera, S.K. Virtual MIMO-based cooperative communication for energy-constrained wireless sensor networks. IEEE Trans. Wirel. Commun. 2006, 5, 984-989. [CrossRef]

25. Cui, S.; Goldsmith, A.J.; Bahai, A. Energy-constrained modulation optimization. IEEE Trans. Wirel. Commun. 2005, 4, 2349-2360.

26. Costa, F.M.; Ochiai, H. A Comparison of Modulations for Energy Optimization in Wireless Sensor Network Links. In Proceedings of the IEEE in Global Telecommunications Conference (GLOBECOM 2010), Maiami, FL, USA, 6-10 December 2010; pp. 1-5.

27. Misra, S.; Kumar, M.P.; Obaidat, M.S. Connectivity preserving localized coverage algorithm for area monitoring using wireless sensor networks. Comput. Commun. 2011, 34, 1484-1496. [CrossRef]

28. Karasabun, E.; Korpeoglu, I.; Aykanat, C. Active node determination for correlated data gathering in wireless sensor networks. Comput. Netw. 2013, 57, 1124-1138. [CrossRef]

29. Anastasi, G.; Conti, M.; di Francesco, M.; Passarella, A. Energy conservation in wireless sensor networks: A survey. Ad Hoc Netw. 2009, 7, 537-568. [CrossRef]

30. Carrano, R.C.; Passos, D.G.; Magalhães, L.C.S.; Vinicius, N.C. Survey and taxonomy of duty cycling mechanisms in Wireless Sensor Networks. IEEE Commun. Surv. Tutor. 2014, 16, 181-194. [CrossRef]

31. de Paz Alberola, R.; Pesch, D. Duty cycle learning algorithm (DCLA) for IEEE 802.15.4 beacon-enabled wireless sensor networks. Ad Hoc Netw. 2012, 10, 664-679. [CrossRef]

32. Wan, Z.; Tan, Y.; Yuen, C. Review on Energy Harvesting and Energy Management for Sustainable Wireless Sensor Networks. In Proceedings of the IEEE 13th International Conference on Communication Technology (ICCT), Jinan, China, 25-28 September 2011; pp. 362-367.

33. Sudevalayam, S.; Kulkarni, P. Energy harvesting sensor nodes: Survey and implications. IEEE Commun. Surv. Tutor. 2011, 13, 443-461. [CrossRef]

34. Nintanavongsa, P.; Naderi, M.Y.; Chowdhury, K.R. Medium Access Control Protocol Design for Sensors Powered by Wireless Energy Transfer. In Proceedings of the IEEE in INFOCOM, Turin, Italy, 14-19 April 2013; pp. 150-154. 
35. Shi, Y.; Xie, L.; Hou, Y.T.; Sherali, H.D. On Renewable Sensor Networks with Wireless Energy Transfer. In Proceedings of the IEEE in INFOCOM, Shanghai, China, 10-15 April 2011; pp. 1350-1358.

36. Li, K.; Luan, H.; Shen, C.-C. Qi-ferry: Energy-Constrained Wireless Charging in Wireless Sensor Networks. In Proceedings of the IEEE in Wireless Communications and Networking Conference (WCNC), Paris, France, 1-4 April 2012; pp. 2515-2520.

37. Erol-Kantarci, M.; Mouftah, H.T. Suresense: Sustainable wireless rechargeable sensor networks for the smart grid. IEEE Wirel. Commun. 2012, 19. [CrossRef]

38. Kumar, D.; Aseri, T.C.; Patel, R. EEHC: Energy efficient heterogeneous clustered scheme for wireless sensor networks. Comput. Commun. 2009, 32, 662-667. [CrossRef]

39. Li, H.; Liu, Y.; Chen, W.; Jia, W.; Li, B.; Xiong, J. COCA: Constructing optimal clustering architecture to maximize sensor network lifetime. Comput. Commun. 2013, 36, 256-268. [CrossRef]

40. Radi, M.; Dezfouli, B.; Bakar, K.A.; Lee, M. Multipath routing in wireless sensor networks: Survey and research challenges. Sensors 2012, 12, 650-685. [CrossRef] [PubMed]

41. Lu, Y.M.; Wong, V.W.S. An energy-efficient multipath routing protocol for wireless sensor networks. Int. J. Commun. Syst. 2007, 20, 747-766.

42. Ergen, S.C.; Varaiya, P. Optimal Placement of Relay Nodes for Energy Efficiency in Sensor Networks. In Proceedings of the IEEE International Conference on Communications (ICC'06), Istanbul, Turkey, 11-15 June 2006; pp. 3473-3479.

43. Misra, S.; Majd, N.E.; Huang, H. Constrained Relay Node Placement in Energy Harvesting Wireless Sensor Networks. In Proceedings of the IEEE 8th International Conference on Mobile Adhoc and Sensor Systems (MASS), Valencia, Spain, 17-22 October 2011; pp. 25-34.

44. Dandekar, D.R.; Deshmukh, P. Energy Balancing Multiple sink Optimal Deployment in Multi-Hop Wireless Sensor Networks. In Proceedings of the IEEE 3rd International on Advance Computing Conference (IACC), Ghaziabad, India, 22-23 February 2013; pp. 408-412.

45. Rajagopalan, R.; Varshney, P.K. Data aggregation techniques in sensor networks: A survey. IEEE Commun. Surv. Tutor. 2006, 8, 48-63. [CrossRef]

46. Fasolo, E.; Rossi, M.; Widmer, J.; Zorzi, M. In-network aggregation techniques for wireless sensor networks: A survey. IEEE Wirel. Commun. 2007, 14. [CrossRef]

47. Wang, S.; Vasilakos, A.; Jiang, H.; Ma, X.; Liu, W.; Peng, K. Energy Efficient Broadcasting Using Network Coding Aware Protocol in Wireless Ad Hoc Network. In Proceedings of the IEEE International Conference on Communications (ICC), Kyoto, Japan, 5-9 June 2011; pp. 1-5.

48. Correia, L.H.; Macedo, D.F.; Santos, A.L.d.; Loureiro, A.A.; Nogueira, J.M.S. Transmission power control techniques for wireless sensor networks. Comput. Netw. 2007, 51, 4765-4779. [CrossRef]

49. Nosratinia, A.; Hunter, T.E.; Hedayat, A. Cooperative communication in wireless networks. IEEE Commun. Mag. 2004, 42, 74-80. [CrossRef]

50. Jung, J.W.; Wang, W.; Ingram, M.A. Cooperative Transmission Range Extension for Duty Cycle-Limited Wireless Sensor Networks. In Proceedings of the 2nd International Conference on Wireless Communication, Vehicular Technology, Information Theory and Aerospace \& Electronic Systems Technology (Wireless VITAE), Chennai, India, 28 February-3 March 2011; pp. 1-5.

51. Musku, M.R.; Chronopoulos, A.T.; Popescu, D.C. Joint Rate and Power Control Using Game Theory. In Proceedings of the 3rd IEEE Consumer Communications and Networking Conference (CCNC 2006), Las Vegas, NV, USA, 8-10 January2006; pp. 1258-1262.

52. Zhou, P.; Liu, W.; Yuan, W.; Cheng, W. Energy-Efficient Joint Power and Rate Control Via Pricing in Wireless Data Networks. In Proceedings of the IEEE Wireless Communications and Networking Conference, Las Vegas, NV, USA, 31 March-3 April 2008; pp. 1091-1096.

53. Tsiropoulou, E.E.; Vamvakas, P.; Papavassiliou, S. Joint utility-based uplink power and rate allocation in wireless networks: A non-cooperative game theoretic framework. Phys. Commun. 2013, 9, $299-307$. [CrossRef]

54. Musku, M.R.; Chronopoulos, A.T.; Popescu, D.C.; Stefanescu, A. A game-theoretic approach to joint rate and power control for uplink CDMA communications. IEEE Trans. Commun. 2010, 58, 923-932. [CrossRef]

55. Alsharif, M.H.; Kim, J. Optimal Solar Power System for Remote Telecommunication Base Stations: A Case Study Based on the Characteristics of South Korea's Solar Radiation Exposure. Sustainability 2016, 8, 942. [CrossRef] 
56. Tutuncuoglu, K.; Yener, A. Communicating using an energy harvesting transmitter: Optimum policies under energy storage losses. IEEE Trans. Wirel. Commun. 2012. Available online: https://arxiv.org/abs/1208.6273 (accessed on 1 July 2019).

57. Zhang, F.; Hackworth, S.A.; Liu, X.; Chen, H.; Sclabassi, R.J.; Sun, M. Wireless Energy Transfer Platform for Medical Sensors and Implantable Devices. In Proceedings of the Annual International Conference of the IEEE in Engineering in Medicine and Biology Society (EMBC 2009), Minneapolis, MN, USA, 3-6 September 2009; pp. 1045-1048.

58. Jonah, O.; Georgakopoulos, S.V. Efficient Wireless Powering of Sensors Embedded in Concrete Via Magnetic Resonance. In Proceedings of the IEEE International Symposium on Antennas and Propagation (APSURSI), Boston, MA, USA, 18-13 July 2011; pp. 1425-1428.

59. Griffin, B.; Detweiler, C. Resonant Wireless Power Transfer to Ground Sensors from a UAV. In Proceedings of the IEEE international conference on Robotics and automation (ICRA), St. Paul, MN, USA, 14-18 May 2012; pp. 2660-2665.

60. Ho, S.; Wang, J.; Fu, W.; Sun, M. A comparative study between novel witricity and traditional inductive magnetic coupling in wireless charging. IEEE Trans. Magn. 2011, 47, 1522-1525. [CrossRef]

61. Kurs, A.; Karalis, A.; Moffatt, R.; Joannopoulos, J.D.; Fisher, P.; Soljačić, M. Wireless power transfer via strongly coupled magnetic resonances. Science 2007, 317, 83-86. [CrossRef] [PubMed]

62. Kline, M.; Izyumin, I.; Boser, B.; Sanders, S. Capacitive Power Transfer for Contactless Charging. In Proceedings of the Twenty-Sixth Annual IEEE in Applied Power Electronics Conference and Exposition (APEC), Fort Worth, TX, USA, 6-11 March 2011; pp. 1398-1404.

63. Popovic, Z. Cut the cord: Low-power far-field wireless powering. IEEE Microw. Mag. 2013, 14, 55-62. [CrossRef]

64. Hui, S. Planar wireless charging technology for portable electronic products and Qi. Proc. IEEE 2013, 101, 1290-1301. [CrossRef]

65. Lu, X.; Wang, P.; Niyato, D.; Kim, D.I.; Han, Z. Wireless charging technologies: Fundamentals, standards, and network applications. IEEE Commun. Surv. Tutor. 2016, 18, 1413-1452. [CrossRef]

66. Lu, X.; Wang, P.; Niyato, D.; Kim, D.I.; Han, Z. Wireless networks with RF energy harvesting: A contemporary survey. IEEE Commun. Surv. Tutor. 2015, 17, 757-789. [CrossRef]

67. Shinohara, N. The wireless power transmission: Inductive coupling, radio wave, and resonance coupling. Wiley Interdiscip. Rev. Energy Environ. 2012, 1, 337-346. [CrossRef]

68. Xie, L.; Shi, Y.; Hou, Y.T.; Lou, A. Wireless power transfer and applications to sensor networks. IEEE Wirel. Commun. 2013, 20, 140-145.

69. Liu, H. Maximizing Efficiency of Wireless Power Transfer with Resonant Inductive Coupling; International Baccalaureate Program; Sir Winston Churchill Secondary School: Vancouver, BC, Canada, 2011; pp. 1-22.

70. Jawad, A.M.; Nordin, R.; Gharghan, S.K.; Jawad, H.M.; Ismail, M. Opportunities and challenges for near-field wireless power transfer: A review. Energies 2017, 10, 1022. [CrossRef]

71. Mur-Miranda, J.O.; Fanti, G.; Feng, Y.; Omanakuttan, K.; Ongie, R.; Setjoadi, A. Wireless Power Transfer Using Weakly Coupled Magnetostatic Resonators. In Proceedings of the IEEE in Energy Conversion Congress and Exposition (ECCE), Portland, OR, USA, 23-27 September 2010; pp. 4179-4186.

72. Gurakan, B.; Ozel, O.; Yang, J.; Ulukus, S. Energy cooperation in energy harvesting communications. IEEE Trans. Commun. 2013, 61, 4884-4898. [CrossRef]

73. Varshney, L.R. Transporting Information and Energy Simultaneously. In Proceedings of the IEEE International Symposium on Information Theory, Toronto, ON, Canada, 6-11 July 2008; pp. 1612-1616.

74. Huang, K.; Zhou, X. Cutting the last wires for mobile communications by microwave power transfer. IEEE Commun. Mag. 2015, 53, 86-93. [CrossRef]

75. Perera, T.D.P.; Jayakody, D.N.K.; Sharma, S.K.; Chatzinotas, S.; Li, J. Simultaneous wireless information and power transfer (SWIPT): Recent advances and future challenges. IEEE Commun. Surv. Tutor. 2017, 20, 264-302. [CrossRef]

76. Gungor, V.C.; Hancke, G.P. Industrial wireless sensor networks: Challenges, design principles, and technical approaches. IEEE Trans. Ind. Electron. 2009, 56, 4258-4265. [CrossRef] 
77. Akyildiz, I.F.; Melodia, T.; Chowdhury, K.R. A survey on wireless multimedia sensor networks. Comput. Netw. 2007, 51, 921-960. [CrossRef]

78. Peer, M.; Jain, N.; Bohara, V.A. A hybrid Spectrum Sharing Protocol for Energy Harvesting Wireless Sensor Nodes. In Proceedings of the 2016 IEEE 17th International Workshop on Signal Processing Advances in Wireless Communications (SPAWC), Edinburgh, UK, 3-6 July 2016; pp. 1-6.

79. Guo, S.; Wang, F.; Yang, Y.; Xiao, B. Energy-efficient cooperative for simultaneous wireless information and power transfer in clustered wireless sensor networks. IEEE Trans. Commun. 2015, 63, 4405-4417. [CrossRef]

80. Tong, B.; Li, Z.; Wang, G.; Zhang, W. How Wireless Power Charging Technology Affects Sensor Network Deployment and Routing. In Proceedings of the IEEE 30th International Conference on Distributed Computing Systems, Genova, Italy, 21-25 June 2010; pp. 438-447.

81. Nishimoto, H.; Kawahara, Y.; Asami, T. Prototype Implementation of Ambient RF Energy Harvesting Wireless Sensor Networks. In Proceedings of the SENSORS, 2010 IEEE, Waikoloa, HI, USA, 1-4 November 2010; pp. 1282-1287.

82. Popović, Z.; Falkenstein, E.A.; Costinett, D.; Zane, R. Low-power far-field wireless powering for wireless sensors. Proc. IEEE 2013, 101, 1397-1409. [CrossRef]

83. Zhang, X.; Jiang, H.; Zhang, L.; Zhang, C.; Wang, Z.; Chen, X. An energy-efficient ASIC for wireless body sensor networks in medical applications. IEEE Trans. Biomed. Circuits Syst. 2010, 4, 11-18. [CrossRef]

84. Guo, S.; Wang, C.; Yang, Y. Mobile Data Gathering with Wireless Energy Replenishment in Rechargeable Sensor Networks. In Proceedings of the Proceedings IEEE INFOCOM, Turin, Italy, 14-19 April 2013; pp. 1932-1940.

85. Guo, S.; Wang, C.; Yang, Y. Joint mobile data gathering and energy provisioning in wireless rechargeable sensor networks. IEEE Trans. Mob. Comput. 2014, 13, 2836-2852. [CrossRef]

86. Wang, C.; Li, J.; Ye, F.; Yang, Y. NETWRAP: An NDN based real-time wireless recharging framework for wireless sensor networks. IEEE Trans. Mob. Comput. 2014, 13, 1283-1297.

87. Zhang, S.; Wu, J.; Lu, S. Collaborative Mobile Charging for Sensor Networks. In Proceedings of the IEEE 9th International Conference on Mobile Ad-Hoc and Sensor Systems (MASS 2012), Las Vegas, NV, USA, 8-11 October 2012; pp. 84-92.

88. Johnson, J.; Basha, E.; Detweiler, C. Charge Selection Algorithms for Maximizing Sensor Network Life with UAV-Based Limited Wireless Recharging. In Proceedings of the IEEE Eighth International Conference on Intelligent Sensors, Sensor Networks and Information Processing, Melbourne, Australia, 2-5 April 2013; pp. 159-164.

89. Naderi, M.Y.; Chowdhury, K.R.; Basagni, S.; Heinzelman, W.; De, S.; Jana, S. Experimental Study of Concurrent Data and Wireless Energy Transfer for Sensor Networks. In Proceedings of the IEEE Global Communications Conference, Austin, TX, USA, 8-12 December 2014; pp. 2543-2549.

90. Wang, Z.; Bulut, E.; Szymanski, B.K. Energy Efficient Collision Aware Multipath Routing for Wireless Sensor Networks. In Proceedings of the IEEE International Conference on Communications (ICC'09), Dresden, Germany, 14-18 June 2009; pp. 1-5.

91. Liu, A.; Ren, J.; Li, X.; Chen, Z.; Shen, X.S. Design principles and improvement of cost function based energy aware routing algorithms for wireless sensor networks. Comput. Netw. 2012, 56, 1951-1967. [CrossRef]

92. Younis, M.; Akkaya, K. Strategies and techniques for node placement in wireless sensor networks: A survey. Ad Hoc Netw. 2008, 6, 621-655. [CrossRef]

93. Yan, Z.; Subbaraju, V.; Chakraborty, D.; Misra, A.; Aberer, K. Energy-Efficient Continuous Activity Recognition on mobile Phones: An Activity-Adaptive Approach. In Proceedings of the 16th International Symposium on Wearable Computers (ISWC), Newcastle Upon Tyne, UK, 18-22 June 2012; pp. 17-24.

94. Hou, I.-H.; Tsai, Y.-E.; Abdelzaher, T.F.; Gupta, I. Adapcode: Adaptive Network Coding for Code Updates in Wireless Sensor Networks. In Proceedings of the 27th IEEE Conference on Computer Communications (INFOCOM 2008), Phoenix, AZ, USA, 15-17 April 2008; pp. 1517-1525.

95. Ray, P.P. A survey on Internet of Things architectures. J. King Saud Univ. Comput. Inf. Sci. 2018, 30, $291-319$.

96. Rida, A.; Yang, L.; Tentzeris, M.M. RFID-Enabled Sensor Design and Applications, 1st ed.; Artech House: Norwood, MA, USA, 2010. 
97. Khan, M.A.; Sharma, M.; Prabhu, B.R. A survey of RFID tags. Int. J. Recent Trends Eng. 2009, 1, 68.

98. Farren, N.; Milou, C.; Volakos, P. The Evolution of Car Parking: Technology Creating Risk and Opportunity; The Transportation Research Board: Washington, DC, USA, 2015.

99. Silva, B.N.; Khan, M.; Han, K. Towards sustainable smart cities: A review of trends, architectures, components, and open challenges in smart cities. Sustain. Cities Soc. 2018, 38, 697-713. [CrossRef]

100. Abdulkader, O.; Bamhdi, A.M.; Thayananthan, V.; Jambi, K.; Alrasheedi, M. A Novel and Secure Smart Parking Management System (SPMS) Based on Integration of WSN, RFID, and IoT. In Proceedings of the 15th Learning and Technology Conference (L\&T), Jeddah, Saudi Arabia, 25-26 February 2018; pp. 102-106.

101. Rivera, J.A.; Fox, J.A.; Grimwood, D. Vehicle Location Tracking Systems and Methods. U.S. Patent Application No. 20180374365, 2018.

102. Tsiropoulou, E.E.; Baras, J.S.; Papavassiliou, S.; Sinha, S. RFID-based smart parking management system. Cyber-Phys. Syst. 2017, 3, 22-41. [CrossRef]

103. Debus, W. RF Path Loss E Transmission Distance Calculations; Axonn, LLC: New York, NY, USA, 2006.

104. Ba, H.; Demirkol, I.; Heinzelman, W. Passive wake-up radios: From devices to applications. Ad Hoc Netw. 2013, 11, 2605-2621. [CrossRef]

105. Massimo, A. Enabling the Internet of Things from Integrated Circuits to Integrated Systems, 1st ed.; Springer: Berlin, Germany, 2017; Chapter 15.

106. Guan, M.; Liao, W.-H. Characteristics of energy storage devices in piezoelectric energy harvesting systems. J. Intell. Mater. Syst. Struct. 2008, 19, 671-680. [CrossRef]

107. Carmo, J.; Rocha, R.; Silva, A.; Gonçalves, L.; Correia, J. Integrated Thin-Film Rechargeable Battery in a Thermoelectric Scavenging Microsystem. In Proceedings of the International Conference on Power Engineering, Energy and Electrical Drives (POWERENG'09), Lisboa, Portugal, 18-20 March 2009; pp. 359-362.

108. Yeo, J.; Moon, S.G.; Jung, J.Y. Antennas for a battery-assisted RFID tag with thin and flexible film batteries. Microw. Opt. Technol. Lett. 2008, 50, 494-498. [CrossRef]

109. Grbović, P.J.; Delarue, P.; le Moigne, P. Selection and Design of Ultra-Capacitor Modules for Power Conversion Applications: From Theory to Practice. In Proceedings of the 7th International Conference in Power Electronics and Motion Control (IPEMC), Harbin, China, 2-5 June 2012; pp. 771-777.

110. Varley, J.; Martino, M.; Poshtkouhi, S.; Trescases, O. Battery and Ultra-Capacitor Hybrid Energy Storage System and Power Management Scheme for Solar-Powered Wireless Sensor Nodes. In Proceedings of the 38th Annual Conference on IEEE Industrial Electronics Society (IECON), Montreal, QC, Canada, 25-28 October 2012; pp. 4806-4811.

111. Wang, Z.L. Toward self-powered sensor networks. Nano Today 2010, 5, 512-514. [CrossRef]

112. Milici, S.; Lázaro, A.; Villarino, R.; Girbau, D.; Magnarosa, M. Wireless wearable magnetometer-based sensor for sleep quality monitoring. IEEE Sens. J. 2018, 18, 2145-2152. [CrossRef]

113. Mardonova, M.; Choi, Y. Review of wearable device technology and its applications to the mining industry. Energies 2018, 11, 547. [CrossRef]

114. Sharma, A.; Pande, T.; Aroul, P.; Soundarapandian, K.; Lee, W. Circuits and Systems for Energy Efficient Smart Wearables. In Proceedings of the IEEE International Electron Devices Meeting (IEDM), San Francisco, CA, USA, 3-7 December 2016; pp. 6.2.1-6.2.4.

115. Klair, D.K.; Chin, K.-W.; Raad, R. A survey and tutorial of RFID anti-collision protocols. IEEE Commun. Surv. Tutor. 2010, 12, 400-421. [CrossRef]

116. Namboodiri, V;; Gao, L. Energy-aware tag anticollision protocols for RFID systems. IEEE Trans. Mob. Comput. 2010, 9, 44-59. [CrossRef]

117. Li, Z.; Zhao, H.; Su, X.; Wan, C. Asymmetric Cryptography Based Unidirectional Authentication Method for RFID. In Proceedings of the 2018 International Conference on Cyber-Enabled Distributed Computing and Knowledge Discovery (CyberC), The Hague, The Netherlands, 19-23 July 2018; pp. 374-3743.

118. Jadhao, A.; Ugale, S. Study of RFID Authentication Protocols. In Proceedings of the Fourth International Conference on Computing Communication Control and Automation (ICCUBEA), Pimpri-Chinchwad, India, 17-18 August 2018; pp. 1-4.

119. Sha, K.; Wei, W.; Yang, T.A.; Wang, Z.; Shi, W. On security challenges and open issues in Internet of Things. Future Gener. Comput. Syst. 2018, 83, 326-337. [CrossRef] 
120. Seliem, M.; Elgazzar, K.; Khalil, K. Towards Privacy Preserving IoT Environments: A Survey. Wirel. Commun. Mob. Comput. 2018, 2018. [CrossRef]

121. Juels, A. RFID security and privacy: A research survey. IEEE J. Sel. Areas Commun. 2006, 24, 381-394. [CrossRef] 